\title{
Effect of Self-reported Height on Occupational Rank Among Police Officers: Especially for Women it Pays to be Tall
}

\author{
Abraham P. Buunk ${ }^{1}$ (I) Gert Stulp ${ }^{2} \cdot$ Wilmar B. Schaufeli $^{3}$
}

Received: 1 October 2020 / Revised: 26 March 2021 / Accepted: 30 March 2021 / Published online: 22 April 2021

(c) The Author(s) 2021

\begin{abstract}
This study among 725 male and 247 female police officers from The Netherlands examined the association between selfreported height and occupational rank from the perspective of sexual selection. Male and female police officers were taller than the average population. A larger percentage of women than of men was found in the lowest ranks, but in the leadership positions, there was a similar percentage of women as of men. Overall, but especially among women, height was linearly associated with occupational rank: the taller one was, the higher one's rank. These effects were independent of educational level and age. The implications for evolutionary theorizing from the perspective of sexual selection on the effect of tallness on status and dominance among women are discussed.
\end{abstract}

Keywords Height $\cdot$ Occupational status $\cdot$ Sex differences $\cdot$ Leadership $\cdot$ Police

Throughout the evolution of many species, height has been an important trait subject to sexual selection. Darwin (1871) suggested that males were larger than females in most mammals because males compete more strenuously for access to mates, and large size is advantageous in such contests. Among mammals, larger males are more likely to win fights against smaller males (Archer, 1988), and thus tend to occupy higher social ranks and to show more social dominance (e.g., Andersson, 1994), which enhances both access to resources and to females. For humans, there is also evidence to suggest that height is related to physical dominance: taller men are physically stronger (e.g., Carrier, 2011; Puts, 2010), are more aggressive, and have better fighting ability (e.g., Archer \& Thanzami, 2007). The importance

Key Findings Dutch police officers in general, but especially women, had higher ranks the taller they were, independent of their educational level and age.

Abraham P. Buunk

a.p.buunk@rug.nl

1 University of Groningen, Netherlands Interdisciplinary Demographic Institute, and Universidad Católica del Uruguay, Groningen, The Netherlands

2 University of Groningen, Groningen, The Netherlands

3 KU Leuven, Belgium and Utrecht University, Utrecht, The Netherlands of height for dominance is illustrated by the use in many cultures of the term "big men," according to Ellis (1994, p. 279) "a conflation of physical size and social rank and ... 'big men' are consistently big men, tall in stature." An interesting study in a virtual environment showed that men, but not women, showed a larger comfortable distance from taller confederates, which was interpreted as height being a signal of dominance and fighting ability (Pazhoohi et al., 2019). Nevertheless, unlike what often is assumed, there is evidence that women may also engage in physical struggles over dominance. For instance, Burbank (1987) observed that in $61 \%$ of the 137 cultures she analyzed, women engaged in physical aggression, typically fighting with other women over men.

Physical strength and fighting ability are unlikely to be major determinants of social status in modern Western societies, given that individuals are prohibited by law from using force against another individual. Nevertheless, in present Western cultures, height is consistently related to income, the attainment of leadership positions, and other measures of professional success (e.g., Judge \& Cable, 2004; Mueller \& Mazur, 2001). As a noteworthy example, US presidents are in general taller than the average American man, and the tallest presidential candidate is most likely to win the most popular votes (Stulp et al., 2013a). Even in homogeneous occupational settings, this association is apparent: one study found that full professors were 0.47 inches taller 
than associate professors, who were 0.26 inches taller than assistant professors, who were 1.24 inches taller than the average nonacademic (Hensley, 1993). To give an example from a quite different field, professional football referees at the World Cup in 2010 were over $4 \mathrm{~cm}$ taller than their assistants (Stulp et al., 2012a).

The fitness of tall men is apparent from the preference of women for taller men that has been shown in many studies, a preference that is stronger than the preference of men for shorter women (e.g., Stulp et al., 2013b). Also in present societies, taller men still tend to have relatively more reproductive success. Nettle (2002) found that men who were taller than average were more likely to find a long-term partner, to have several different long-term partners, and to have children, although not to have a greater mean number of children. According to Nettle, this suggests that, in a noncontracepting environment, they would have more children. Even more evidence for the fitness of tall men was found by Mueller and Mazur (2001) who showed in a cohort of military officers that height was positively with the number of children, which was due to having more often a second or subsequent wife. Selection worked strongly in favor of very tall men, not just against short men. As there were no hints of any evolutionary check on this selection, the authors suggested an unconstrained directional selection for tallness in men. However, there is also evidence for stabilizing selection, since extremely tall men tend to have an excess of health problems and an increased likelihood of childlessness, suggesting that while male tallness has been selected for in recent evolution, it has been constrained by developmental factors and stabilizing selection on the extremely tall (Stulp et al., 2012b).

The effects of height on status and reproductive success are more complex among women than among men. Most studies on the association of height with status show that the magnitudes of the effects are stronger for men than for women, and that selection has favored height more for men than for women (e.g., Judge \& Cable, 2004), and that for men, being tall leads to more positive perceptions by others than for women (e.g., Jackson \& Ervin, 1992). Illustrative are the findings by Deady and Smith (2006) who found that among pre-reproductive women (aged 20-29), increasing height was related to a lower importance of having children, lower maternal tendencies, a lower ideal number of children, and an older ideal own age to have one's first child, but to a higher importance of having a career, and a stronger career competitiveness. In the same line, among post-reproductive women (aged over 45), increasing height was actually associated with having fewer children, with having had one's first child at older age, and with the importance of having a career. A large longitudinal study showed that shorter women had more children surviving to age 18 than taller women, despite increased child mortality in shorter women.
Taller women had a higher age at first birth and at first marriage and reached a higher social status, but the negative effect of height on reproductive success persisted after controlling for these variables (Stulp et al., 2012c). In addition, very short and very tall women are more prone to illnesses than women of average height (Silventoinen et al., 1999), and women of approximately average height have relatively more reproductive success in Western societies (Nettle, 2002; cf. Buunk et al., 2009).

The evolutionary background of the adaptive significance of height is reflected in what has been referred to as "heightism" (e.g., Rosenburg, 2009). Indeed, there is a plethora of research that shows that taller people are perceived as more competent, intelligent, authoritative, dominant, and better leaders (e.g., Cinnirella \& Winter, 2009; Judge \& Cable, 2004; Marsh et al., 2009; Re et al., 2013; Young \& French, 1996; Blaker et al., 2013). These positive biases may at least in part be proximate mechanisms through which taller individuals occupy more often higher occupational positions and are more likely to attain leadership positions.

The aim of the present research was to expand current knowledge on the association between height and status for women and men by examining in a Dutch sample the relation between self-reported height and rank among male and female police officers. Interestingly, one may argue that heightism is also manifest in the selection of police officers. Kirchengast (2010) examined minimum height requirements for police officers in Europe (in about 50\% of the countries examined such requirements existed) and found that the main reasons reported for height standards were that taller heights of police officers implicate power and status, that tallness is associated with physical fitness, and that tallness has psychological benefits. Indeed, one might expect that tallness might make much police work easier as there is for example evidence that on the street, people are significantly more likely to give way to taller individuals than to shorter individuals (Stulp et al., 2015). This study is quite relevant for police work, given the fact that police work often requires dominance in interpersonal confrontations, for example when writing out a fine, when making an arrest, or when maintaining order. A study among police officers showed indeed that shorter officers had a greater potential for aggression and issued more warnings than did taller individuals, assumedly because they had less natural ascendancy than taller officers (Willoughby \& Blount, 1985). Even more so, especially in the police force where officers have to deal with male and female civilians, short women may be at a "double disadvantage," being a woman as well as being shorter than most women (and even more so than most men), thus making it relatively difficult to exercise authority. Of course, height may be not of overwhelming importance in police work as police officers have received defense training, carry a weapon, and are often joined by another officer. Even 
more so, a study by Lagestad (2012) found that short police students of both sexes generally perform better in physical tests than tall police students.

The present research is particularly relevant as it is only relatively recently that women were allowed to make a career in the police force. Although in The Netherlands, in 1911, already the first female police officer was appointed-as inspector for a vice squad-it took more than three quarters of a century for women to attain career opportunities in the police force, as it was only in 1971 that women were admitted to the Dutch Police Academy, the educational institute for police officers in leadership positions. For a long time, women were not considered to have the right personality characteristics for being a police officer. Even in 1979, more than half of the police forces did not have any female police officer, but since 1985, there has been a policy of positive discrimination to select more women in the police force, a process that did not go smoothly particularly due to resistance of male police officers of various ranks (De Graaf \& Van der Wal, 2011). Given this development, for descriptive reasons, the distribution of men and women over the various occupational ranks was also examined. When assessing the effects of height as well as gender on occupational rank, it was also examined if these effects were independent of educational level and age, as those who had a higher education and had spent more time in the police force might have had a higher chance of reaching a higher occupational rank.

\section{Method}

\section{Sample and Procedure}

A random stratified sample $(n=3740)$ was drawn from the national Dutch police force in 2014. The response rate was $41 \%(n=1535)$, but only those on active duty were selected to participate in the current study, excluding administrative personnel and officers in training, as both groups were not part of the promotion system for those on active duty. The study was approved by the Research and Documentation Centre (WODC) of the Dutch Ministry of Justice and Security according to their strict ethical standards. The Ethical Committee of the Department of Psychology did not evaluate non-experimental studies. The final sample included 975 police officers; the majority were men $(n=725)$, and about a quarter were women $(n=247)$. The distribution of the Dutch police ranks was in ascending order: surveillant $3.2 \%$, agent $4.4 \%$, hoofdagent $26.9 \%$, brigadier $37.4 \%$, inspecteur $15.5 \%$, hoofdinspecteur or commissaris 9.4\% (both latter categories were combined because there were only 6 women in the category of hoofdinspecteur). These Dutch police ranks correspond roughly to those in the UK of police constable, sergeant, inspector, chief inspector, superintendent, and chief superintendent, respectively.
The self-reported height of men in the present sample was $M=184 \mathrm{~cm}(S D=0.07 \mathrm{~cm})$, with a minimum of $158 \mathrm{~cm}$ and a maximum of $207 \mathrm{~cm}$; for women, these figures were $M=172 \mathrm{~cm}(S D=6 \mathrm{~cm})$, with a minimum of $157 \mathrm{~cm}$ and a maximum of $190 \mathrm{~cm}$. Quite obviously, the sex difference was significant, $t(970)=25.45, p<0.001$. In the Netherlands, no minimal height is required for police officers. Nevertheless, on average, the police officers were significantly taller than people of 20 years and older in the Dutch population in 2017; for men, the population mean was $M=181 \mathrm{~cm}$, $t(724)=10.19, p=0.00$, and for women, $M=167 \mathrm{~cm}$, $t(246)=11.66, p<0.001$. There is considerable evidence for the validity of self-reported height. For example, although Ekström et al. (2015) found that people tend to overestimate their height with on average $0.5 \mathrm{~cm}$, these authors still found a correlation of 0.98 between self-reported and actual height. Additional evidence for the validity of self-reported height comes from a study by Lasalle et al. (2013) among 2513 participants that showed an intraclass correlation of 0.94 . Thus, it seems acceptable to examine correlations of self-reported height and variables like occupational rank.

The age distribution was as follows: $3.5 \%$ was between 22 and 24 years of age, $17.2 \%$ between 25 and 34 years, $21.5 \%$ between 35 and 44 years, 34\% between 45 and 54 years, and $23.8 \%$ between 55 and 64 years. Men working at the police $(M=46.97, S D=10.79)$ were on average almost 7 years older than women $(M=40.10, S D=9.33), t(972)=8.98$, $p<0.001$. In addition, men $(M=6.86, S D=6.54)$ worked on average around 2 years longer in their present job than women $\operatorname{did}(M=4.82, S D=4.21), t(969)=4.60, p<0.001$.

The educational level varied considerably and was in ascending order: $1 \%$ had only primary school, $17.2 \%$ had the lower level of high school, $22.8 \%$ had a lower professional education, 25.8 had the higher level of high school, 15.8\% had a bachelor degree, and $7.2 \%$ had a university master or doctoral degree. Women $(M=3.80, S D=1.17)$ were on average more highly educated than men $(M=3.56, S D=1.14)$, $t(973)=2.88, p<0.01$.

\section{Results}

\section{Distribution Over Ranks}

First, the differences between men and women in occupational rank were assessed and how occupational rank was related to age and educational level. A crosstabs analysis showed that there was a significant difference between gender and occupational rank, $\mathrm{Chi}^{2}(5,975)=45.99, p<0.001$, a small to moderate effect size, Cohen's $w=0.22$. Men $(M=6.12, S D=1.27)$ had on average a higher occupational rank than women, $(M=5.72, S D=1.44), t(970)=25.45$, $p=0.00, t(973)=4.19, p<0.001$, a moderate effect size, 
Cohen's $d=0.29$. However, it was not the case that the higher the occupational rank, the fewer women there were (see Fig. 1). In terms of percentage of the total number within each gender, there were indeed more women $(6.4 \%)$ than men $(2.1 \%)$ at the lowest level (constable), about as many men $(4.1 \%)$ as women $(5.2 \%)$ at the next level (sergeant), and more women $(38.8 \%)$ than men $(22.8 \%)$ at the next level on the occupational ladder, that of inspector. However, in the next two levels - that of chief inspector and superintendent - there were relatively more men $(40.4 \%$ and $21.1 \%$ ) than women ( $28.8 \%$ and $11.2 \%)$. Remarkably, at the highest level, there were similar percentage of both sexes, for men $9.4 \%$ and for women $9.6 \%$. To examine if the effect of gender on rank was upheld when controlling for age and educational level, the generalized linear model option from SPSS was used, with occupational rank as dependent variable and gender, age, and educational level as predictors. The tests of model effects showed that both educational level, Wald Chi ${ }^{2}(1)=574.49, p<0.000$, with Cohen's effect size $w=0.77$, as well as age, Wald $\mathrm{Chi}^{2}(1)=253.93, p=0.00$, with Cohen's effect size $w=0.51$, had highly significant and quite strong effects on occupational rank. Nevertheless, gender still had a weak, though significant effect, Wald $\mathrm{Chi}^{2}$ $(1)=10.72, p<0.001$, with Cohen's effect size $w=0.10$.

\section{Effect of Self-Reported Height on Rank}

Next, the major issue of the current study was examined, i.e., how self-reported height is associated with occupational rank for men and for women. Again, the generalized linear model option was employed, with occupational rank as dependent variable and gender and self-reported height as predictors. First, the Wald $\mathrm{Chi}^{2}$ 's as shown in the tests of model effects, was examined, and next the values of $B$ as shown in the parameter estimates. The results showed significant effects of height, Wald $\mathrm{Chi}^{2}(1)=20.39$, $p=0.00$, with Cohen's effect size $w=0.14, B=1.60$. (SE 0.16, 3.04), and of gender, Wald $\mathrm{Chi}^{2}(1)=6.53$, $p<0.05$, with Cohen's effect size $w=0.08, B=7.16$ (SE $1.67,12.65)$. The effect of self-reported height was much stronger than that of gender, and implied that, overall, the taller one reported that one was, the higher one's occupational rank, whereas the effect of gender indicated that men had on average a higher occupational rank. However, these effects were qualified by a significant interaction, Wald $\mathrm{Chi}^{2}(1)=6.37, p<0.05$, with Cohen's effect size $w=0.08, B=4.06$. (SE 0.91, 7.21).

To interpret the interaction, generalized linear model analyses were executed for men and women separately. For women, the effect of self-reported height was highly significant, Wald $\mathrm{Chi}^{2}(1)=13.65, p<0.001$, with Cohen's effect size $w=0.23, B=5.66$ (SE 2.66, 8.66). For men, the effect of self-reported height was also significant, albeit considerably weaker than for women, Wald $\mathrm{Chi}^{2}(1)=4.97, p<0.05$, with Cohen's effect size $w=0.08, B=0.72$ (SE 0.19, 3.00). To present the findings in a transparent way, in Fig. 2, rank is displayed on the $X$-axis and height on the $Y$-axis. This figure shows that with increasing occupational rank, average self-reported height was higher, but that this effect was particularly manifest among women (except in the two lowest levels). The average difference in self-reported height between the lowest and highest occupational rank was about $5.0 \mathrm{~cm}(S D=0.8)$ for women and $3.7 \mathrm{~cm}(S D=0.5)$ for men. As even the average self-reported height of women in the highest rank $(174 \mathrm{~cm})$ was still well below the average height for men, it is not the case that women are expected to be
Fig. 1 Percentage of women and of men in the various ranks. The percentages refer to the percentage within each sex in a given rank. Numbers in white represent sample sizes in each rank

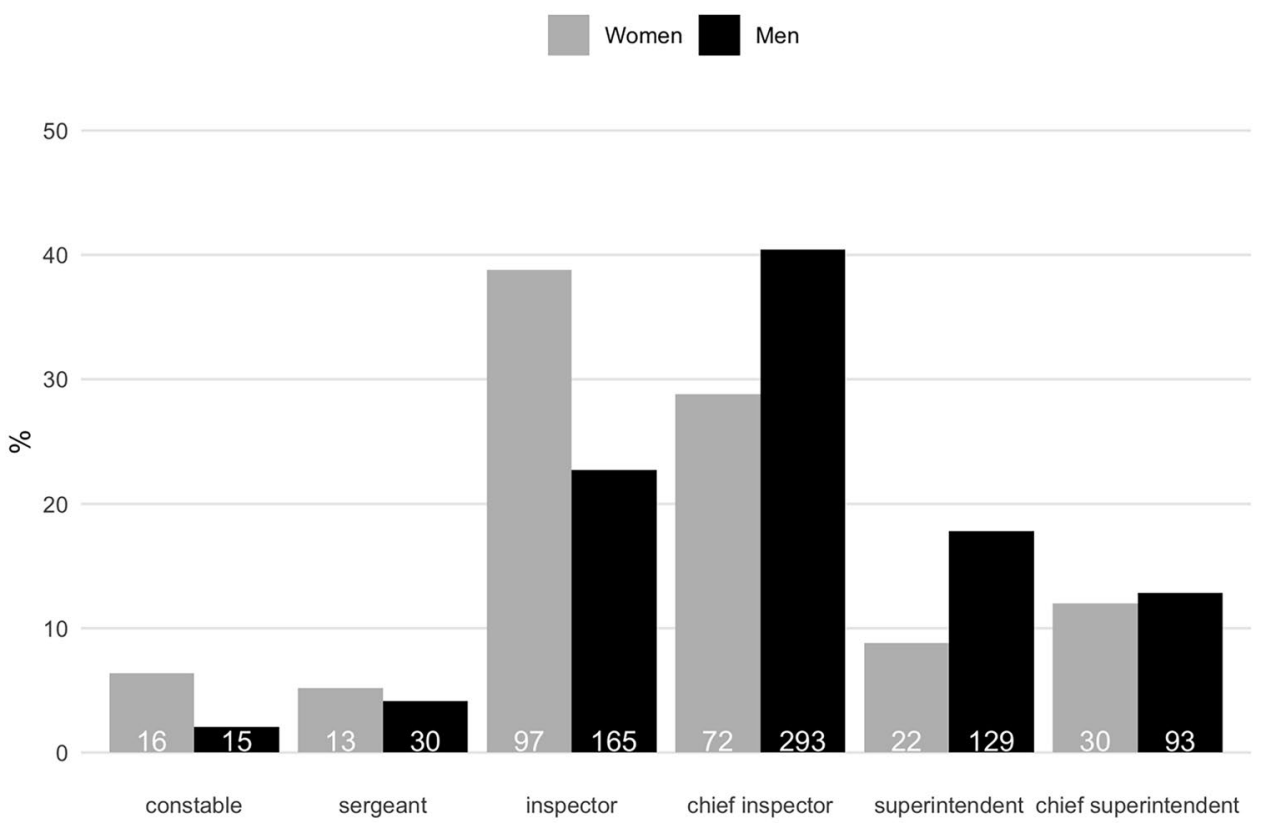


Fig. 2 Police rank and height for men and women. The grey dots are the raw data points. The black dot and error bars represent the mean and $95 \%$ confidence interval. The black dashed line represents the mean height in the sample for that sex. Numbers in grey represent sample sizes per rank

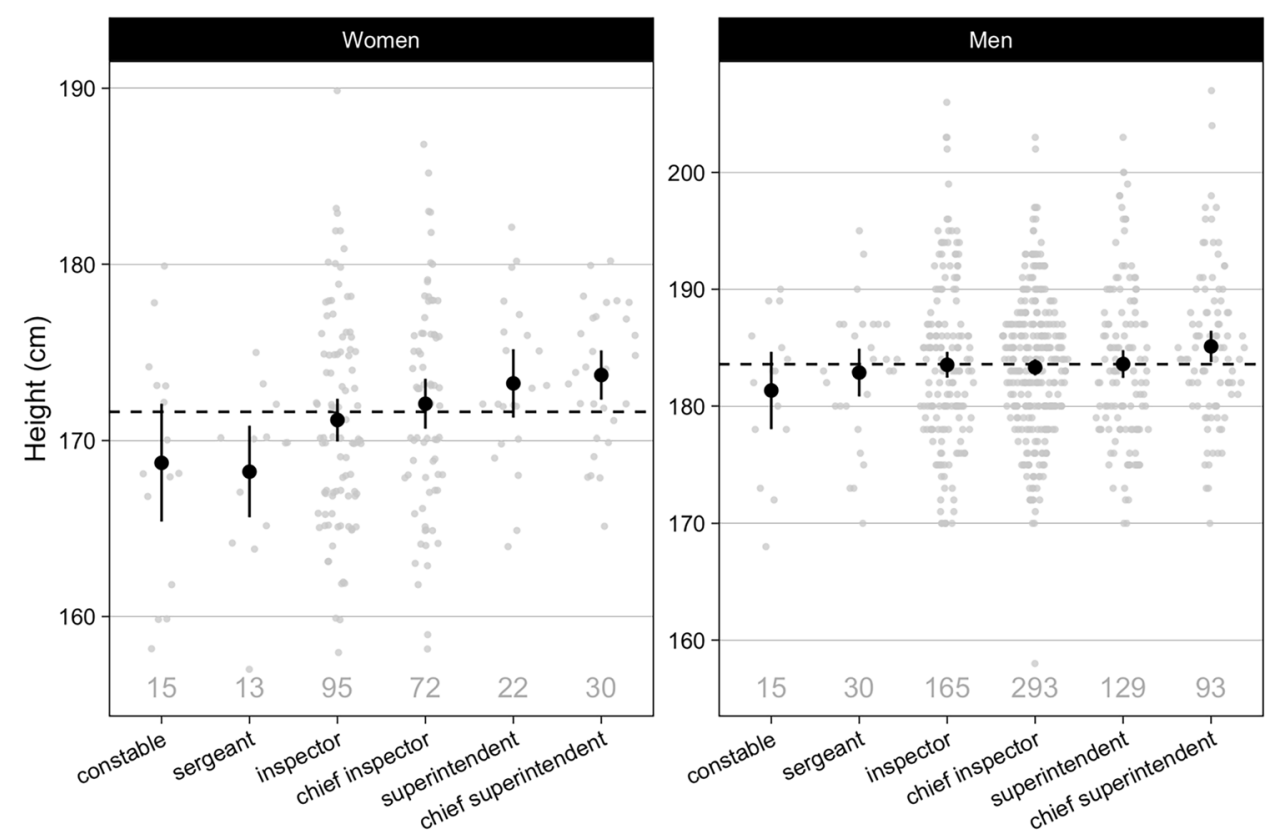

extremely tall to advance in rank. From Fig. 2, it is also clear that there are some quite tall people in the lower ranks, and similarly, some quite short people in the higher ranks.

Finally, with generalized linear model analyses, it was examined if the effects for both genders were upheld when controlling for educational level and age, two variables that may obviously be related to occupational rank, as in general, one needs more education and more experience to move up in rank. Indeed, both educational level and age had highly significant effects among men as well as women (all $p$ 's $<0.001$ ). Nevertheless, for both men and women, the effects of self-reported height stayed virtually the same (for women, Wald $\mathrm{Chi}^{2}(1)=11.71, p<0.001$, for men Wald $\left.\mathrm{Chi}^{2}(1)=5.229, p<0.05\right)$. That the effects of self-reported height remained intact when controlling for two clearly powerful variables, underlines, despite the small effect sizes, the robustness of the height effects in the present sample.

\section{Discussion}

The present study examined if among police officers selfreported height is related to occupational rank. It was expected that overall, taller officers would be higher in rank than short officers, and thus more likely to attain important leadership positions. Substantial evidence was found for this prediction. Unlike what one would expect on the basis of sexual selection theory and what has in generally been found previously (e.g., Judge \& Cable, 2004), the association between self-reported height and occupational rank was much stronger among women than among men. Among women, from the rank of sergeant, there was a linear increase in self-reported height up till the highest rank of chief superintendent, suggesting that a woman's career opportunities in the police force are affected by their height. Although the association between self-reported height and occupational rank for men was much weaker than among women, for men as well as for women the-statistical—effects of self-reported height were maintained when controlling for two factors that may be related to occupational rank, i.e., age and educational level. However, age might not necessarily be a reliable indicator of rank in such occupations as many officers may retire without having attained a high rank, and some officers may even be degraded in rank as a punishment. Furthermore, it must be noted that the effect sizes were small, and that there were some quite tall people in the lower ranks, and similarly some quite short people in the higher ranks. Nevertheless, in general, the present findings are in line with many studies that have shown that height is associated with rank and salary in organization (e.g., Judge \& Cable, 2004).

There may be various reasons why the effect of selfreported height on occupational rank was much stronger for female than for male police officers. First, as women are shorter than men are, given the importance of having a kind of natural authority and physical strength as a police officer when dealing with the public, in the selection and promotion, more-though not necessarily conscious-attention may be paid to women's height. Second, although there is evidence that women of medium height may feel they are most popular with the opposite sex (Stulp et al., 2013c), the present research fits with the evidence that taller women tend to be more career oriented (Deady \& Smith, 2006; see also Buunk et al., 2019). Given the emphasis on affirmative 
action and given the positive stereotypes of tall people, taller women may be selected more likely for leadership positions than short women. Indeed, although this is no longer true for the Netherlands, as noted in the Introduction, in many European countries, there is a minimum height required for entering the police force (Kirchengast, 2010), and it is possible that in the Netherlands, still norms from the past play a role in hiring and promotion of police officers.

Although one might consider the association between self-reported height and occupational rank in the police organization in part as a result of unfounded prejudice against short people (cf. Lagestad, 2012), in police work, it may be to some extent functional to base one's decisions to hire or promote tall women as they might be more effective in dealing with the public, especially with difficult situations involving male law transgressors. Taller people have simply an advantage in daily interactions. The present findings suggest that this was not the case: officers in the lowest levels of occupational rank were among men and women shorter than officers in the higher levels. Interestingly, there is some evidence that short officers may have better physical skills (Lagestad, 2012), which help them in fulfilling their tasks adequately.

In the present research, it was not possible to examine the influence of childhood environments on height, but this would be an important venue to examine in future research. Even though height is for about $80 \%$ heritable (e.g., McEvoy \& Visscher, 2009; Perola et al., 2007), psychosocial stress and malnutrition during childhood do all adversely affect growth (e.g., Silventoinen, 2003; Cavelaars et al., 2000; Mascie-Taylor, 1991; Nyström Peck \& Lundberg, 1995). A positive association between self-reported height and occupational status, especially among women, as found in the present research may be in part a result of one's childhood environment, which not only positively affects height but also health (Silventoinen et al., 1999) and cognitive abilities (Case \& Paxson, 2008). Nevertheless, the present findings are in line with other studies that showed that, even when controlling for family background, height may be positively associated with socioeconomic status (e.g., Magnussen et al., 2006), and with social skills (Persico et al., 2004; Cinnirella \& Winter, 2009).

Given the relatively recent opening of leadership positions to women in The Netherlands, there were a number of relevant descriptive findings on the rank of women in the police force. First, although there were numerically fewer women in the highest level, the percentage of women at that level was the same as that of men. This may indicate that currently, there is less discrimination of women than before when it comes to top positions in the Dutch police organization. Second, the effect of gender on occupational rank was small and smaller than that of educational level and age. This suggests that one of the reasons that there are more men than women in the higher ranks may in part be due to the fact that women have only recently entered the Dutch police force in substantial numbers, and therefore are younger, and have had less time to build up the necessary experience to advance up in the organization. Women in the present sample were indeed on average nearly 7 years younger than men. Nevertheless, educational level had a strong effect on occupational rank, and female officers were more highly educated than male officers. In future research, it would be important to unravel the precise processes underlying the effects of height, educational level, and gender on the rank in the police force.

Finally, the current research has a number of potential limitations. First, as noted above, the effect sizes were not very large. Second, like in most studies, self-reported height rather than actual height was assessed, and individuals may overestimate their height. However, as noted in the "Method," there is considerable evidence for a very high correlation between self-reported and actual height (Ekström et al., 2015; Lasalle et al., 2013). Moreover, there is evidence that actual height is in a similar way associated with for example status and attractiveness as self-reported height (e.g., Stulp et al., 2013c). A third potential limitation of the present findings is that these may be particularly relevant for organizations where physical dominance is an advantage, including not only the police but also for example fire brigades, the armed forces, or rescue services.

To conclude, the present research suggests that in organizations, at least self-reported height may be associated more strongly with status and dominance among women than among men. Given the finding that there is evidence that short police students of both sexes generally perform better in physical tests than tall police students (Lagestad, 2012), it seems possible that also stereotypes may play a role, inducing halo effects favoring taller people, without paying enough attention to their actual qualifications. However, in general, it seems that such halo effects do occur more with respect to men than with respect to women (e.g., Jackson \& Ervin, 1992). It is important to examine in future research which processes are responsible for the effect of height on organizational rank, and especially for sex differences in this respect. In any case, the present research may hopefully increase in general the awareness of the potential importance of height of women in a specific type of organizational settings, i.e., the police force, a phenomenon that has received relative attention in research so far.

Acknowledgements The authors thank Toon Taris for all his work on designing and conducting the research.

Author Contribution Abraham Buunk did most of the writing. Gert Stulp and Wilmar Schaufeli commented on this. Gert Stulp did parts of the data analyses and made the figures. Wilmar Schaufeli had the leading role in designing and conducting the research. 
Data Availability The data are available upon the request to the corresponding author.

\section{Declarations}

Ethical Approval The research was subsidized by the Research and Documentation Centre (WODC) of the Dutch Ministry of Justice and Security, and approved by this ministry according to their strict ethical standards.

Competing Interests The authors declare no competing interests.

Open Access This article is licensed under a Creative Commons Attribution 4.0 International License, which permits use, sharing, adaptation, distribution and reproduction in any medium or format, as long as you give appropriate credit to the original author(s) and the source, provide a link to the Creative Commons licence, and indicate if changes were made. The images or other third party material in this article are included in the article's Creative Commons licence, unless indicated otherwise in a credit line to the material. If material is not included in the article's Creative Commons licence and your intended use is not permitted by statutory regulation or exceeds the permitted use, you will need to obtain permission directly from the copyright holder. To view a copy of this licence, visit http://creativecommons.org/licenses/by/4.0/.

\section{References}

Andersson, M. (1994). Sexual selection. Princeton: Princeton University Press.

Archer, J. (1988). The behavioural biology of aggression. Cambridge (UK): Cambridge University Press.

Archer, J. \& Thanzami, V. (2007). The relation between physical aggression, size and strength, among a sample of young Indian men. Personality and Individual Differences, 43: 627-633. https:// doi.org/10.1016/j.paid.2007.01.005

Blaker, N. M., Rompa, I., Dessing, I. H., Florijn Vriend, A., Herschberg, C., $\&$ Van Vugt, M. (2013). The height leadership advantage in men and women: testing evolutionary psychology predictions about the perceptions of tall leaders. Group Processes and Intergroup Relations, 16, 17-27. https://doi-org.proxy-ub.rug.nl/10.1177/1368430212437211

Burbank, V. K. (1987). Female aggression in cross-cultural perspective. Behavior Research, 21, 70-100. https://doi-org.proxy-ub.rug.nl/ $10.1177 / 106939718702100103$

Buunk, A.P., Fernandez, A.M., \& Muñoz Reyes, A.M. (2019). Height as related to self-perceived mate value and attractiveness. Evolutionary Behavioral Sciences, 13, 93-100. https://doi-org.proxy-ub. rug.nl/10.1037/ebs0000132

Buunk, A.P., Pollet, T.V., Klavina, L., Figueredo, A.J., Dijkstra P. (2009). Height among women is curvilinearly related to life history strategy. Evolutionairy Psychology, 4, 545-559. https://doiorg.proxy-ub.rug.nl/10.1177/147470490900700405

Carrier, D.R. (2011) The advantage of standing up to fight and the evolution of habitual bipedalism in Hominins. PLoS ONE, 6. https:// doi.org/10.1371/journal.pone.0019630

Case, A., \& Paxson, C. (2008). Stature and status: height, ability, and labor market outcomes. Journal of Political Economy, 116, 499532. https://doi.org/10.1086/589524

Cinnirella, F. \& Winter, J. (2009). Size Matters! Body height and labor market discrimination: a cross-European analysis, CESifo Working Paper, No. 2733

Darwin, C. (1871). The descent of man, and selection in relation to sex. London, England: John Murray; 1871.
Cavelaars, A.E.J.M., Kunst, A.E., Geurts J.J.M., R., Grotvedt, L., Helmert, U., Lahelma, E., Lundberg, O., Mielck, A., Rasmussen, N.K., Regidor, E., Spuhler, T. \& Mackenbach, J.P. (2000). Persistent variations in average height between countries and between socio-economic groups: an overview of 10 European countries. Annals of Human Biology, 27, 407-421. https://doi.org/10.1080/ 03014460050044883

Deady, D. K., \& Smith, M. J. L. (2006). Height in women predicts maternal tendencies and career orientation. Personality and Individual Differences, 40(1), 17-25. https://doi-org.proxy-ub. rug.nl/10.1016/j.paid.2005.06.014

De Graaf, M., \& Van der Wal, R. (2011). Op de schouders van voorgangers, streven naar diversiteit in de Nederlandse politietop [On the shoulders of predecessors: aiming at diversity in the Dutch police top]. Apeldoorn, The Netherlands: Politieacademie.

Ekström, S., Kull, I., Nilsson, S., \& Bergström, A. (2015). Web-based self-reported height, weight, and body mass index among Swedish adolescents: a validation study. Journal of Medical Internet Research, 17(3). https://doi.org/10.2196/jmir.3947

Ellis, L. (1994). The high and the mighty among men and beast: How universal is the relationship between height (or body size) and social status. In L. Ellis (Ed.), Social stratification and socioeconomic inequality. Reproductive and interpersonal aspects of dominance and Status, vol. 2 (pp. 93-111). Westport: Praeger.

Hensley, W. E. (1993). Height as a measure of success in academe. Psychology: A Journal of Human Behavior, 30, 40-46.

Jackson, L. A., \& Ervin, K. S. (1992). Height stereotypes of women and men: The liabilities of shortness for both sexes. The Journal of Social Psychology, 132(4), 433-445. https://doi.org/10.1080/ 00224545.1992 .9924723

Judge, T.A., \& Cable, D.M. (2004). The effect of physical height on workplace success and income: preliminary test of a theoretical model. The Journal of Applied Psychology, 89: 428-441. https:// doi-org.proxy-ub.rug.nl/10.1037/0021-9010.89.3.428

Kirchengast, S. (2010). Minimum body height requirements for police officers - an international comparison, SIAK-Journal - Zeitschrift für Polizeiwissenschaft und Polizeiliche Praxis, 4, 41-49. http:// dx.doi.org/10.7396/2010_4_E

Lagestad, P. (2012). It's not the size that matters: physical skills among tall and short police students. International Journal of Police Science \& Management, 14, 322-333.

Lassale, C., Péneau, S., Touvier, M., Julia, C., Galan, P., Hercberg, S., \& Kesse-Guyot, E. (2013). Validity of web-based self-reported weight and height: results of the Nutrinet-Santé study. Journal of Medical Internet Research, 15(8), 4-16. https://doi-org.proxy-ub. rug.nl/10.2196/jmir.2575

Magnusson, P. K., Rasmussen, F. \& Gyllensten, U. B. (2006). Height at age 18 years is a strong predictor of attained education later in life: cohort study of over 950000 Swedish men. International Journal of Epidemiology 35, 658-663. https://doi.org/10.1093/ije/dy1011

Marsh, A.A., Yu, H.H., Schechter, J.C., \& Blair, R.J.R. (2009). Larger than life: humans' nonverbal status cues alter perceived size. PLoS ONE, 4: e5707. https://doi.org/10.1371/journal.pone.0005707

Mascie-Taylor, C. G. N. (1991). Biosocial influences on stature: a review. Journal of Biosocial Science, 23, 113- 128. https://doiorg.proxy-ub.rug.nl/10.1017/S0021932000019131

McEvoy, B. \& Visscher, P. (2009). Genetics of Human Height. Economics and Human Biology, 7, 294-306. https://doi.org/10.1016/j. ehb.2009.09.005

Mueller, U., \& Mazur, A. (2001). Evidence of unconstrained directional selection for male tallness. Behavioral Ecology and Sociobiology, 50, 302-311. https://doi.org/10.1007/s002650100370

Nettle, D. (2002). Height and reproductive success in a cohort of British men. Human Nature, 473-491. https://doi-org.proxy-ub.rug. $\mathrm{nl} / 10.1007 / \mathrm{s} 12110-002-1004-7$ 
Nyström Peck, M., \& Lundberg, O. (1995). Short stature as an effect of economic and social in childhood. Social Science \& Medicine, 41, 733-738. https://doi.org/10.1016/0277-9536(94)00379-8

Pazhoohi, F., Silva, C., Lamas, J., Mouta, S., Santos, J., \& Arantes, J. (2019). The effect of height and shoulder-to-hip ratio on interpersonal space in virtual environment. Psychological research, 83, 1184-1193.

Perola, M., Sammalisto, S., Hiekkalinna, T., Martin, N. G., Visscher, P. M., Montgomery, G.W., Benyamin, B. et al. (2007) Combined genome scans for body stature in 6,602 European twins: evidence for common Caucasian loci. PLoS Genetics, 3:e97 https://doi.org/10.1371/journal. pgen.0030097

Persico, N., Postlewaite, A. \& Silverman, D. (2004). The effect of adolescent experience on labor market outcomes: the case of height. Journal of Political Economy, 112, 1019 1053. https://doi.org/10. $1086 / 422566$

Puts, D. A. (2010). Beauty and the beast: Mechanisms of sexual selection in humans. Evolution and Human Behavior, 31, 157-175. https://doi.org/10.1016/j.evolhumbehav.2010.02.005

Re, D. E., DeBruine, L. M., Jones, B. C., \& Perrett, D. I. (2013). Facial cues to perceived height influence leadership choices in simulated war and peace contexts. Evolutionary Psychology, 11, 89-103. https://doi.org/10.1177/147470491301100109

Rosenburg, I. B. (2009). Height discrimination in employment. Utah Law Review, 3, 907.

Silventoinen, K. (2003). Determinants of variation in adult body height. Journal of Biosocial Science, 35, 263-285. https://doi.org/10.1017/ S0021932003002633

Silventoinen, K., Lahelma, E., \& Rahkonen, O. (1999). Social background, adult body-height and health. International Journal of Epidemiology, 28, 911-918. https://doi.org/10.1093/ije/28.5.911

Stulp, G., Buunk, A.P., Kurzban, R., \& Verhulst, S. (2013c). The height of choosiness: mutual mate choice for stature results in sub-optimal pair formation for both sexes. Animal Behaviour, 86, 37-46. https:// doi.org/10.1016/j.anbehav.2013.03.038
Stulp, G., Buunk, A.P., \& Pollet, T.V. (2013b). Women want taller men more than men want shorter women. Personality and Individual Differences, 54, 877-883. https://doi.org/10.1016/j.paid.2012.12.019

Stulp, G., Buunk, A.P., Verhulst, S., \& Pollet, T.V. (2012a). High and mighty: height increases authority in professional refereeing. Evolutionary Psychology, 10, 588-601. https://doi.org/10.1177/ 147470491201000314

Stulp, G., Buunk, A.P., Verhulst, S., \& Pollet, T.V. (2013a). Tall claims? Sense and nonsense about the importance of height of US presidents. The Leadership Quarterly, 24, 159-171. https:// doi.org/10.1016/j.leaqua.2012.09.002

Stulp, G., Buunk, A.P., Verhulst, S., \& Pollet, T.V. (2015). Human height is positively related to interpersonal dominance in dyadic interactions. PLOS ONE, 10, [e0117860 https://doi.org/10.1371/journal. pone. 0117860

Stulp, G., Pollet, T.V., Verhulst, S., \& Buunk, A.P. (2012b). A curvilinear effect of height on reproductive success in human males. Behavioral Ecology and Sociobiology, 66, 375-384. https://doi.org/10.1007/ s00265-011-1283-2

Stulp, G., Verhulst, S., Pollet, T.V. \& Buunk, A.P. (2012c). The effect of female height on reproductive success is negative in Western populations, but more variable in non-Western populations. American Journal of Human Biology, 24, 486-494. https://doi.org/10. 1007/s00265-011-1283-2

Willoughby, K. R., \& Blount, W. R. (1985). The relationship between law enforcement officer height, aggression, and job performance. Journal of Police Science \& Administration, 13(3), 225-229.

Young, T.J. \& French, L.A. (1996). Height and perceived competence of U.S. presidents. Perceptual and Motor Skills, 82, 1002. https:// doi-org.proxy-ub.rug.nl/10.2466/pms.1996.83.1.153

Publisher's Note Springer Nature remains neutral with regard to jurisdictional claims in published maps and institutional affiliations. 